\title{
DINÁMICA DEL DEBATE PÚBLICO SOBRE LA INMIGRACIÓN
}

\author{
IDYNAMICS OF THE PUBLIC DEBATE ON IMMIGRATION
}

\author{
Tomás Pedro Gomariz Acuña \\ Universidad Rey Juan Carlos, Madrid. España/Spain \\ tomas.gomariz@urjc.es
}

Recibido/Received: 03/06/09

Aceptado/Accepted: 14/09/09

\section{RESUMEN}

La inmigración ha sido, durante casi diez años, uno de los temas frecuentes en la opinión pública, unas veces provocada por la masiva llegada de personas a este país y por los motivos más diversos, otras por las disputas entre los distintos partidos del ámbito parlamentario español y, por último pero sin intención de agotar el tema, por la posición de muchos ciudadanos y ciudadanas que defendían, también, posturas encontradas ante este fenómeno recurrente en la historia de la humanidad. Lo que se pretende es presentar un marco teórico sobre el tema, plantear la dinámica en la que se desenvuelve la forma de entender esta realidad por los principales agentes cívicos y políticos de nuestra sociedad.

\section{PALABRAS CLAVE}

Inmigración, exclusión, conflicto intercultural, diálogo social, opinión pública, partidos políticos, Habermas.

\begin{abstract}
Immigration has been, during almost ten years, one of the frequent topics in the public opinion, sometimes caused by the massive arrival of people in this country and for various reasons, others by the disputes between the various parliamentary parties Spanish and, last but not intended to exhaust the topic, the position of many citizens who defended, also, opposing views at this recurrent phenomenon in human history. The aim is to present a theoretical framework on the issue and to raise the dynamic in which operates the way to understand this reality by the main civic and political actors of our society.
\end{abstract}

\section{KEYWORDS}

Immigration, exclusion, intercultural conflict, social dialogue, public opinion, political parties, Habermas.

\section{INTRODUCCIÓN}

El interés del estudio del debate público sobre la inmigración responde a múltiples razones. Entre ellas, el entendimiento del efecto provocado por el fenómeno migratorio en 
la conciencia solidaria de la ciudadanía y la comprensión de la mecánica de superación de nuestro sistema político. La situación de desamparo de los inmigrantes ha motivado el desarrollo de la discusión social en torno a las deficiencias de los soportes de legitimidad del orden existente. Con ello se ha evidenciado la disponibilidad del marco institucional presente, que enriquece su estabilidad y perseverancia en la cohesión discursiva de la concurrencia plural. De esta forma, podemos apreciar como la vigencia de la lógica del debate desarrollado sobre la pretensión de la culminación del ideal kantiano de estabilidad y paz, que sólo podía ser alcanzado en el supuesto del estado cosmopolita, refuerza una moralidad que da amparo a la búsqueda de alternativas para el progreso social, el debido desarrollo institucional y, por consiguiente, la integración de la diversidad cultural.

Las claves de la armonía y la estabilidad se encuentran en la concurrencia racional del diálogo. Los fundamentos de la cohesión social, que sostienen la democracia de mercado, se establecen en la mediación que acometen los interlocutores cívicos. Esto se produce así, sobre todo, cuando las distancias entre los agregados sociales se definen por razones de índole étnica. En tal circunstancia, un acontecimiento incuestionable, cuando triunfa el equilibrio, es que la dinámica de la ética discursiva termina por convertirse en fundamento rector de las estructuras del entorno socialmente instituido.

Desde las crisis sociales y políticas de los años sesenta, hemos asistido al desenvolvimiento cíclico de diferentes movimientos sociales que han ido cuestionando el orden creado tras la Segunda Guerra Mundial. En profundidad, destacando sus aportaciones más importantes, se debe señalar como éstos han motivado una nueva apertura del debate político a la influencia de la sociedad. Con ellos, el crecimiento de la importancia del debate público ha subido por encima del interés de la discusión parlamentaria. Lógicamente, el primero ha trascendido hasta la esfera donde se produce la última. Claramente, el resultado ha consistido en dar un paso más en el desarrollo de nuestro sistema democrático. Con la prominencia de la sociedad civil se han ido abriendo más espacios a la participación ciudadana, en los lugares donde se discute y se decide sobre las materias relativas al interés general. A la vez, al margen de la institucionalización de las estructuras organizativas de la protesta y de la consiguiente creación de órganos consultivos de los gobiernos, el poder de la opinión pública, en sí mismo, se ha ido haciendo más pertinente en los procesos de elaboración de las decisiones políticas.

En el caso del presente estudio se atiende un fenómeno de reciente generación: la lógica discursiva del movimiento cívico de solidaridad con la población inmigrante en España. Su singularidad se debe, en gran medida, a la inexistencia de precedentes. Siendo así, nos encontramos ante un conjunto de acciones de protesta que casi surgió de forma súbita. Sin apenas haber tenido tiempo para la formación de los fundamentos causales de las protestas, éstas emergieron con una considerable vitalidad. Aunque no contase con un estado de opinión favorable, sí había unas estructuras organizativas muy bien preparadas para afrontar este tipo de reto. Al respecto se debe de tener en cuenta cómo el número de afectados, inicialmente, era francamente reducido y sus problemas, además de todo, eran ajenos a los intereses de la generalidad de la ciudadanía española.

En definitiva, la generación de este movimiento de presión fue provocado por el menoscabo de las expectativas creadas en el proceso de la consolidación de la democracia en España. La capacidad de respuesta del tejido social, aquí comprometido, a pesar de encontrarse, por aquellas fechas, en un estado muy temprano de formación, se caracterizó por su eficiencia. La causa motora de esta mecánica de actuación tuvo su origen en la promulgación de la primera normativa constitucional que habría de regular la extranjería. 
Para aquel entonces las primeras denuncias sobre esta temática ya habían sido formuladas. La esperanza de la resolución de estos casos estaba puesta en la elaboración de la nueva regulación. La decepción vino motivada por el contenido de la Ley de Extranjería de 1985. En resumidas cuentas, este movimiento tuvo su razón de ser en la percepción de la vulneración de los principios de universalidad del Derecho.

\section{SOPORTES TEÓRICOS}

El tratamiento de la realidad propuesta nos obliga a utilizar una serie de términos que requieren algunas aproximaciones. A este respecto es vital centrar la atención en la controvertida discusión mantenida entre debate de la teoría radical de sistemas de Luhmann la teoría de la competencia comunicativa de Habermas. El debate entre ambas posiciones fue acompañado por la concurrencia de otras aportaciones que en este escrito, por razones de tiempo y espacio yo he obviado. Antes de pasar al detalle, considero importante hacer mención de las contribuciones de Eliabeth Noelle-Neumann: La espiral del silencio (2003), que vino a cuestionar el escenario idílico donde se podía entender las consideraciones del último autor. La concepción del teórico germánico de la opinión pública defendía que los procesos de formación de opinión dependían de la interacción de individuos libres e ilustrados en un proceso de debate público, a través del cual se llegaba a acuerdos con la ayuda de la prensa, que era vista como la voz del público.

\subsection{Contribuciones de la teoría radical de sistemas}

La definición de la comunicación de Luhmann, que en algunos aspectos se separa de la concepción clásica, se realiza mediante las características generales de los sistemas. Ésta es comprendida como un proceso selectivo que tiende a reproducirse a sí mismo. A diferencia de la forma habitual en la que es entendida en el pensamiento sociológico, la comunicación, en este caso, no se basa en un proceso de transmisión de información. Para este autor, el compromiso ontológico del proceso observado por la perspectiva sociológica tradicional, acerca del intercambio de contenidos, es resuelto en el reconocimiento del proceso autoconstitutivo de la información que se produce en el acto de la comunicación. Para Luhmann lo prioritario es el mismo proceso de la comunicación, que crea la realidad y la identidad de la información (Luhmann, 2000).

Distinguiéndose de los conceptos usuales de las perspectivas disciplinares tradicionales, reconoce tres componentes fundamentales de la comunicación: la información, el mensaje y la expectativa de éxito. Con estos la comunicación se convierte en un proceso selectivo compuesto por tres agregados diferentes. La unidad de éstas es la unidad de la comunicación. El primer componente es estimado en cuanto a proceso de selección entre varias alternativas que se produce en el mismo acto de la comunicación. Así, la información se ve afectada por el propio proceso comunicativo. El mensaje refuerza la selección del componente anterior, supone la selección en el componente de la información. La expectativa de éxito se basa en la expectativa de la consumación eficiente de la comunicación. Este componente ordena todo el proceso de la comunicación mediante su fundamentación. Junto a todo esto replantea la concepción de los términos clásicos emisor y receptor, sustituyéndolos por Ego, que comunica, y Alter, que es informado. El autor los define, apartándose de toda referencia a la mera transmisión, mediante la distinción establecida entre información y mensaje. Ambos se constituyen en el mismo 
proceso comunicativo, teniendo en él su propia referencia. Así, la comunicación se construye en el proceso mismo, además de construir a los participantes en ella. Dentro de todo esto, el último proceso de selección, que contiene a los anteriores, es el de la comprensión de todo el proceso comunicativo. Comprensión que consiste en la aceptación o el rechazo del mensaje.

Por último, al respecto de la formulación teórica de Luhmann, se han de tener en cuenta los conceptos necesarios para la comprensión de la forma por la cual se inician y se consuman las selecciones de los procesos comunicativos. Estos son los de código y medio de comunicación simbólicamente generalizado (Luhmann, 2000). A través de ellos se produce la comunicación, que es el núcleo de la reproducción autopoiética de todo sistema social. La función del código es permitir la ejecución del proceso de selección (Luhmann, 2000). Permite ordenar la realidad de forma accesible al sistema. En cuanto al medio de comunicación de nuestro autor, que es expresado en términos parsonianos, éste es entendido como un instrumento que no solamente hace posible una comunicación. Éstos medios a través de la generalización para simbolizar los nexos de unión entre la selección y la motivación imponen la unidad entre diferentes tipos de comunicación permitiendo su variedad, que está basada en la diferencia.

\subsection{Presupuestos generales de la teoría de la acción comunicativa}

Frente a todos estos presupuestos, la teoría de la acción comunicativa de Habermas se había edificado sobre el fundamento antropológico que Luhmann trató de combatir enérgicamente. Por este motivo, en la teoría de este autor la comunicación es considerada como actividad basada en la transmisión de información o contenidos. Procediendo con el contraste de los supuestos de un amplio número de destacados teóricos, no se aisló en un innumerable conjunto de términos abstractos y elaboró un concepto de racionalidad comunicativa basado en el "hilo conductor del entendimiento lingüístico" (Habermas, 1998) que está íntimamente relacionado con los procesos racionales de consentimiento. Partiendo de una teoría del lenguaje procede con el análisis de los rasgos pragmáticos del habla en la sociedad, que es el objeto de su teoría. Habermas, en sentido opuesto al teórico de sistemas, aludido en los párrafos anteriores, que rechaza el estudio de la acción, desarrollo una teoría de la comunicación como alternativa a los fracasos registrados por las teorías precedentes. Así, sitúa el grado de significación de la experiencia social en las actividades de los agentes. La teoría de la acción comunicativa es el principio explicativo de una teoría de la sociedad fundada en una teoría del lenguaje y en el análisis de las estructuras generales de la acción. El rasgo característico de los participantes será la racionalidad manifestada en el "lenguaje"

En esta teoría la acción comunicativa es comprendida como la situación de interacción basada en la mutua comprensión. Al redefinir los tipos weberianos, coloca frente a la acción instrumental la acción comunicativa como una relación interpersonal lingüística que busca el consenso. Cuando la acción comunicativa se basa en argumentaciones racionales $\mathrm{y}$ tiene pretensiones de universalidad se denomina discurso.

"Este concepto de racionalidad comunicativa encierra connotaciones que, en su esencia se fundan en la experiencia central del discurso argumentativo que produce la unión sin coacción y que crea el consenso, proceso en el cual los diversos participantes logran dejar atrás sus creencias, primeramente sólo subjetivas y, gracias a la experiencia común del convencimiento motivado racionalmente adquieren la certeza, 
simultáneamente, de la unidad del mundo objetivo y de la ínter subjetividad del contexto en que desarrollan sus vidas." (Habermas, 1998)

Al desarrollar una teoría del lenguaje abre un camino hacia su aspiración de universalidad. Al conectar el concepto de lenguaje con el de sociedad y con el de mundo de la vida abre la posibilidad de una teoría del lenguaje que concilie la acción con la interpretación. Pretende que la noción de la racionalidad comunicativa esté contenida, implícitamente, en la estructura del habla humana como tal, que significa el estándar básico de la racionalidad compartida por los agentes competentes de las sociedades modernas.

Al respecto de las líneas básicas del pensamiento a desarrollar en el presente artículo, he de señalar dos conceptos fundamentales: el de acción y comunicación. Las teorías presentadas aquí son en gran medida contrapuestas, pero ambas presentan puntos de interés para estas reflexiones. Primero, no desconsiderando la importancia de recurrir al análisis de la forma en la que se produce el acto de comunicación entre actores individuales para poder entender la lógica del acto comunicativo, en mi análisis he desconsiderado estos supuestos al tener que analizar la actividad de actores colectivos. En todo este trabajo de investigación no se ha observado las acciones de ningún actor individual. Siguiendo los planteamientos de Emile Durkheim se ha desconsiderado cualquier tipo de planteamiento psicologicista en el estudio sociológico. No quiero decir con esto que los haya rechazado, porque en el fondo me he limitado a dar por entendido muchas de las valiosas conclusiones obtenidas en este efecto. Por ello he pretendido mantener una línea de análisis no excesivamente alejada de los presupuestos de Luhmann, pero más próxima a las aportaciones del teórico de la Escuela de Frankfurt.

En segundo lugar, quiero justificar mi postura basándome en la crítica del rechazo de Luhmann al soporte antropológico sobre el que se había edificado la sociología clásica. Considero que es oportuno salvar el obstáculo encontrado por la teoría de T. Parsons. Además, por sentido común, y coincidiendo con lo dicho al respecto de los soportes sobre los que se ha de desarrollar el carácter disciplinar de la sociología, quiero volver a destacar que en nuestra labor se han de poner ciertos límites a los presupuestos individualistas, o basados en el análisis de sujetos individuales. De estos ámbitos del saber se pueden obtener muy buenos conocimientos pero es muy arriesgado elaborar sobre este tipo de efecto juicios de validez universal en el estudio de la sociedad. Así, concluyendo, hago expresa la importancia del esquema presentado por Luhmann, no por sus conclusiones, sino en cuanto proporciona un campo conceptual muy útil para la observación y el análisis. Además, también, quiero destacar mi predilección por Habermas en cuanto al conjunto de su pensamiento y al desarrollo, específico, de la teoría de la acción comunicativa.

\section{MECÁNICA DE LOS CONFLICTOS SOCIALES ACTUALES}

Una de las características principales de los nuevos movimientos sociales es la limitación de sus objetivos. En realidad, son un mecanismo de ajuste del orden instituído que emerge cuando los dispositivos institucionales de canalización del debate público alcanzan su obsolescencia. Éstos no surgen con la ambición de producir un cambio sustantivo de la sociedad. Sólo se dirigen a conseguir mejoras en el orden existente. Se concentran en una determinada problemática, a partir de la cual surgió el conflicto, para 
buscar soluciones. No se desarrollan como los movimientos revolucionarios. No cuestionan en su totalidad el marco político y social instituído. Por tanto, el poder de los Estados no es, para ellos, un baluarte a derrocar. Su mecánica evolutiva se define mediante la lógica de la interacción mantenida con los poderes políticos. Cuando su objeto es de carácter político, la mecánica de desarrollo de estos fenómenos se define en la lógica de la interacción mantenida con los gobiernos. Cuando la finalidad es un cambio de actitud en la sociedad el sentido de las acciones está condicionado por los efectos de los mensajes que se tratan de transmitir a la ciudadanía. En general, suelen ser sus objetivos la sensibilización, la disuasión y la interlocución. En sí todos ellos son los objetos del habla.

A tenor de lo destacado en el párrafo precedente, no debemos dejar de señalar que la importancia de la teoría de la competencia comunicativa, de la Segunda Escuela de Frankfurt, se encuentra en el hecho de presentarse como alternativa superadora de los defectos de la teoría clásica de la acción social y del valor de los conocimientos aportados sobre los actos de la comunicación. En esencia toda movilización colectiva es un acto comunicativo donde los defectos del orden político, cultural y social se expresan. El objetivo principal de estas tentativas cívicas es ejercer influencia sobre el debate público y la opinión generalizada de la ciudadanía.

\subsection{Tendencias progresivas de un contexto de cambio: la expresión de las nuevas exigencias de la sociedad}

Superada la dinámica tradicional de los conflictos existentes en la sociedad mediante la instauración del modelo de la posguerra mundial, en occidente, el periodo convulsivo, producido a continuación, marca el inicio de una nueva forma de confrontación caracterizada por la aparición de nuevos agentes de presión, nuevas formas de realizar las protestas y nuevos objetos de reivindicación (Kaese et al., 1992; Habermas, 1985). No solamente se hicieron evidentes las necesidades de modificación de algunos elementos de los escenarios utilizados para la canalización de los conflictos, sino también de algunos de los contenidos manejados en las mecánicas de desarrollo del debate público institucionalizado. Lo que surgió en esta tesitura tuvo como efecto la descomposición del panorama de los conflictos tradicionales. En este trance quedó patente que las organizaciones políticas y sociales predominantes, hasta el momento, en la esfera pública, ya no representaban a los grupos sociales afectados por los defectos del orden existente. Estos agentes ya se habían constituido como elementos integrantes de un modelo existente de sociedad. Por otra parte, lógicamente, por la baja perdurabilidad de los movimientos sociales, no trato de hablar de la aparición de un determinado tipo de interlocutor con los poderes públicos. La emergencia de estos fenómenos proporcionó la prueba evidente del sistema político. Y abrió la vía para la acometida de las acciones de presión frente al orden instituído.

Motivado por las crisis que se anticiparon al último cuarto del siglo XX, donde se hicieron visibles las deficiencias del sistema político para atender las demandas que se iban generando, empezaron a aparecer nuevas formas de movilización que advierten de la crisis del modelo pluralista. El sistema democrático existente cae en decadencia. Las reivindicaciones de mejoras de la sociedad se empiezan a ejercer por otras vías a los canales establecidos por los regímenes políticos existentes (Habermas, 1974). El surgimiento de este nuevo tipo de movilización, más innovadora, va introduciendo nuevas concepciones del mundo (McAdam, 1994). Su forma de organización y de actuación frente a los poderes públicos y la sociedad se sale de los patrones establecidos convencionalmente. Una de las 
principales diferencias mantenidas con los movimientos precedentes es la ausencia de una concepción general del mundo. Sus iniciativas se dirigen hacia la realización de reformas dentro del orden existente (Johnston et al., 1995; Inglehart, 2006; Kaese et al., 1992). En un principio surgieron como iniciativas contra-corporativistas, (Giner, 1993) aunque posteriormente terminarían siendo absorbidas por las estructuras de gobierno.

La crisis de representación de los intereses iniciada en este periodo, progresivamente daría lugar a nuevas formas de interlocución donde, cada vez más, el sistema parlamentario iría viendo reducidas sus facultades. La estabilidad política, posteriormente alcanzada, se basaría en el ensamblaje de una nueva forma de corporativismo (Offe, 1988a). Esto ha supuesto la creación de circuitos paralelos al parlamento. La causa se encuentra en la incapacidad de las estructuras políticas para atender todas las problemáticas y conflictos de intereses existentes en la sociedad. A partir de entonces las negociaciones no irían sólo dirigidas a conseguir el consenso con las demás fuerzas políticas, sino a alcanzarlo con las nuevas fuerzas sociales que estaban emergiendo. Las nuevas organizaciones surgidas como materialización estructural de las movilizaciones irían entrando en el juego de la interlocución. Este paso entrañaba la aceptación de las reglas de la interlocución social, por lo que se hacían más controlables. A este respecto, no se debe olvidar como las dinámicas hasta ahora comprometidas en este documento son producto del modelo de sociedad existente y su predisposición de ruptura total es completamente discutible (Pérez Iruela y Giner, 1988). En sí el proceso del desarrollo de las estructuras corporativas da lugar a la articulación de los intereses colectivos al garantizarse la sostenibilidad de las entidades así creadas con la ayuda proporcionada por los gobiernos.

\subsection{Argumentación de las posturas de los agentes sociales}

Las posturas de los agentes sociales vienen determinadas por una causa motora. En las sociedades democráticas ésta suele ser la apreciación de las contracciones existentes entre la realidad social y la moralidad del orden político. Son puntos donde se evidencian los defectos de las bases de legitimación del modelo social y político establecido. Éstas son las bases desde donde se genera la posterior evolución de toda la mecánica de movilización social. Desde estos soportes se procede al establecimiento de los fundamentos de las iniciativas colectivas. En tal mecánica se encuentra implicado un profundo debate interno de los nuevos actores de la demanda y el desarrollo de la argumentación de la protesta.

\section{Constitución de los soportes ideológicos de los movimientos}

Lo propio de todo de todo movimiento social es la explosión de las actividades de protesta, tal como sucede cuando agitamos una bebida gaseosa. Tras la acumulación de sensaciones de malestar social o ante acontecimientos que provocan profunda consternación se producen este tipo de fenómenos. Pero en el fondo todo esto se produce tras haberse ido fomentando este tipo de situaciones. Previamente, la crítica fue difundiéndose, se fueron generando amplias redes sociales implicadas en estos asuntos y los debates en torno a las materias concernidas se fueron generalizando. La capacidad de movilización de todo tejido social tiene su base en la maduración de una concepción de la realidad incompatible con la situación padecida por una determinada colectividad o comunidad.

Este mecanismo de desarrollo y ajuste de los presupuestos sobre los que se justifican las nuevas reivindicaciones es el resultado de un madurado proceso de discusión entre los afectados por la causa de toda movilización. En sí, en este procedimiento se 
desarrolla la teoría que habrá de guiar las prácticas de movilización. En él, "acción y mundo de vida" convergen para alumbrar nuevas prácticas. Tal vez, en este trasunto no se reproduzcan las condiciones ideales del discurso de la Teoría de la Acción Comunicativa, pero claramente es en él donde mejor se reproducen éstas.

\subsection{Contenido de las demandas sociales}

El fruto del proceso referido en el párrafo anterior es la formulación de las reivindicaciones. La esencia de tal procedimiento es el contraste. Con él se consigue la coherencia del pensamiento que lleva a una colectividad a la acción. En el transcurso de este tipo de acontecimientos se reproducen, en una escala inferior, la misma mecánica que se volverá a dar en la esfera del debate público.

Las diferentes entidades de un entramado social actúan como órganos sensitivos donde se captan los defectos del contexto político y social. A la vez, estas instancias, inician la dinámica de discusión orientada al debate público general. Aquí podemos ver como toda esta madeja de relaciones sigue el funcionamiento de un organismo que constituye su realidad en la auto-referencia de un procedimiento que le lleva a transformar la realidad.

\subsection{Estrategias de confrontación}

Las estrategias seguidas por los diferentes actores del escenario dibujado se definen según su posición en este contexto. En todas estas situaciones de intercambio simbólico se destaca la postura de los poderes públicos justificando lo acontecido en función del interés general y la estabilidad del orden establecido. En su contra, la postura de los agentes de presión social se orienta a la crítica y la denuncia de las contradicciones en el estado de cosas defendida por las instituciones públicas. Así, la fricción termina convirtiéndose en un espectáculo dado al ejercicio de la retórica.

La primera etapa de confrontación siempre se destaca por el choque entre los contendientes. El recurso principal es la descalificación del oponente y la justificación, ante la opinión pública, de la postura mantenida ante el estado de agitación. Posteriormente, introducida la temática objeto de liza en la esfera del debate público, una vez alcanzado los primeros objetivos de la presión, se da lugar al diálogo de los poderes políticos con lo agentes sociales comprometidos en la protesta. Tras esto la naturaleza de las negociaciones de la componenda de fuerzas entre ambos márgenes.

La dinámica de los acontecimientos constitutivos del movimiento cívico desarrollado contra la exclusión social de los inmigrantes, al igual de lo sucedido con otras movilizaciones, se ha caracterizado, principalmente, por la interacción de las posturas mantenidas entre las organizaciones comprometidas con la necesidades del colectivo perjudicado por las condiciones existentes, los poderes públicos, en tanto responsables de la organización del orden establecido y las tendencias de opinión, formadas al efecto, en cuanto actitudes más generalizadas en la sociedad. El desarrollo de la presión ejercida por este movimiento ha sido dirigido en una doble dirección: hacia los órganos e instituciones del Estado, en primer lugar, por medio de las demandas de cambio del marco legal que norma la condición del extranjero en España y la puesta en práctica de las medidas que garanticen la integración social de los miembros de estos colectivos. En segundo lugar, hacia la sociedad, para tratar de influir en la generación de un estado de opinión favorable, mediante la sensibilización de la ciudadanía española al respecto de las dificultades de los extranjeros que viven en nuestro país. 


\section{EVOLUCIÓN DEL DEBATE SOBRE LA EXTRANJERÍA Y LA INMIGRACIÓN}

En el fondo, el debate público surgido sobre esta materia nos pone al descubierto el procedimiento de ajuste del estado español a la nueva situación creada con la entrada en el Mercado Común. Con las ventajas producidas por la transformación económica, se iría generando el llamado "efecto llamada". En este fenómeno no sólo influían las mejoras en las estructuras de generación de riqueza sino la caída de las constantes vitales de nuestro crecimiento demográfico. Mientras la reducción de las tasas de natalidad y de fecundidad facilitaba la estabilidad económica al impedir un fuerte crecimiento del gasto público en materia social, a largo plazo, las posibilidades de crecimiento económico se irían mermando por la falta de recursos humanos. Esta situación terminaría siendo resuelta con la incorporación de mano de obra extranjera. El saldo económico, de todo esto, sin lugar a dudas, es evidentemente beneficioso.

El tratamiento del contexto, donde se produce el objeto de este estudio, requiere de la observación de las diferentes etapas de desarrollo de este proceso. Como he venido señalando, práctica y estructura social se encuentran íntimamente relacionadas. Sobre todo en este tipo de fenómenos, los actores reaccionan ante las condiciones del contexto y a partir de este acto van generando una nueva situación, donde van a tener que seguir actuando. En mi análisis de la lógica evolutiva de la presión social a favor de los inmigrantes, tal como se desarrolla en los capítulos siguientes, he distinguido cinco etapas. Cada una de ellas se diferencia por las características de las iniciativas llevadas a cabo por los agentes participantes. Estas acciones han sido caracterizadas en tanto al móvil o causa, normalmente definido por el contexto, y objeto perseguido en las actividades acometidas, que normalmente supone la modificación de las características de ese marco de la acción. Aunque las protestas a favor de los extranjeros no surgieron como reacción ante la situación existente, sí lo fueron frente a la situación que se iba a crear con la promulgación del nuevo marco legal de la extranjería. En principio fue una reacción social frente a la política gubernamental que daría lugar a un contexto nefasto para una porción considerable de personas que hasta entonces vivían en situación regular en España. Ese marco generado con la promulgación de la Ley $7 / 85$ se mantendría durante el periodo analizado porque, aún a pesar de las protestas, no se conseguiría ni derogar ni cambiar esta ley. Pero gracias a las presiones sociales se conseguirían considerables cambios de la política en la materia.

\subsection{Antecedentes del debate sobre la situación de los extranjeros}

El primer periodo de la evolución del escenario donde se producen los hechos de mi estudio es el de los momentos previos a la promulgación de la Ley 7/85, de 1 de julio de 1985, reguladora de los derechos y libertades de los extranjeros en España. La principal característica de esta etapa es la de la ausencia de un marco legislativo unificado, general y homogéneo. Las únicas normas existentes eran previas a la aprobación de la Constitución de 1978. Éstas, además de ser parciales, se solapaban entre ellas dando lugar a la creación de situaciones de desamparo jurídico e indefensión ante prácticas administrativas abusivas y ante la acción de terceros. Los primeros años de la democracia en España, los de la estabilización política, se caracterizaron por los continuos ajustes a la nueva situación política. Jurídicamente fue un periodo de actualización del marco legal. Un volumen considerable de tratados internacionales, sobre materias humanitarias y sociales, fueron ratificados por nuestro Estado. Así, también era un periodo de muchas expectativas de mejora de las condiciones existentes. 
El tratamiento de la estancia de los extranjeros en España, la condición jurídica de estas personas, se trató de forma diferenciada según cuales fueran las causas del establecimiento de éstos en nuestro país. Para este efecto se confeccionó una legislación general y otra específica para los que venían buscando asilo o refugio. Los textos de ambas leyes supusieron una merma de las expectativas. Pero fue, especialmente, en el caso de la extranjería donde se dio lugar a la generación de una auténtica situación de desagravio. Aunque la aprobación de la Ley 5/1984, de 26 de marzo, reguladora del derecho de asilo y condición del refugiado, no estuvo exenta de polémicas, ésta pudo ser considerada como un auténtico logro. La expectación estuvo provocada por las confrontaciones previas del PSOE con el gobierno de UCD. El principal defecto de las modificaciones de postura socialista fue el de la eliminación de la pretendida oficina de tramitación de las solicitudes (SEPRA) fuera de las instancias del Ministerio del Interior. El carácter benevolente de esta ley fue el motivo principal para que no se produjeran reacciones adversas de la sociedad. Las situaciones polémicas serían provocadas, posteriormente, con los defectos de su aplicación.

El segundo periodo de este proceso vendría definido por la aplicación del nuevo marco legal, generado en las etapas previas y motivado por la presión exterior. Si la puesta en práctica de la Ley de Refugio supuso una merma de lo predispuesto en el texto legal, la Ley de Extranjería era completamente regresiva. Parte del texto fue invalidado con la Sentencia 115/1987 del Tribunal Constitucional sobre el Recurso de inconstitucionalidad núm. 880/1985 de la Ley 7/85 sobre derechos y libertades de los extranjeros en España. El nuevo marco para el desarrollo de la vida de los extranjeros establecidos en España sería muy restrictivo y por tanto desestabilizaría su situación. Se dio el caso de que muchos afectados por la nueva regulación, arraigados completamente en nuestro país, tras muchos años de residencia, perdían su condición jurídica y pasaban a estar en situación irregular. Lo más paradójico era que estas iniciativas fueran promovidas, con bastante torpeza, por una coalición de gobierno plenamente acreditada ante su electorado como progresista. Aún a pesar de la estabilidad que esta circunstancia otorgaba a estos hechos enseguida surgieron fuertes conflictos sociales que pusieron en peligro las relaciones diplomáticas con el país vecino del norte de África. En concreto, este fue el caso de los musulmanes de Ceuta y Melilla aún a pesar de no contar los cuerpos de Seguridad del Estado con los recursos necesarios. Por otra parte, no existía un estado de opinión favorable a la protesta. El problema pasaba desapercibido ante la ciudadanía española. Los extranjeros pobres lejos de provocar sentimientos solidarios alguno eran mirados con desprecio.

\subsection{Apertura del debate público sobre la inmigración y la extranjería}

Los cambios del contexto que definen la tercera etapa fueron provocados por dos hechos: la presión social y el cambio de postura producido en el ámbito comunitario con motivo de ajustar la situación existente antes de la entrada en vigor del Tratado de la Unión Europea (Borras, 1995). La inmigración clandestina era considerada como el principal obstáculo para la supresión de fronteras de la Unión Europea. La gran novedad del momento se produce con las medidas del Gobierno tomadas al efecto, dentro de las líneas básicas de la política española de extranjería: la apertura de los canales de interlocución con la sociedad. La exigencia institucional de ajuste se dirigió a tratar de sacar a la luz cuáles eran las dimensiones de la bolsa de extranjeros en situación irregular y regularizarlos. Estas iniciativas fueron seguidas también por los países del entorno europeo. Curiosamente, incluso, se hablaba de cómo las estadísticas de regularizados se redondeaban en torno a la cifra de cien mil por nación. 
El establecimiento de la política de consenso se inició con el proceso extraordinario de regularización de 1991. Ésta era la primera medida, a llevar a cabo, de la política activa comprometida con la proposición no de Ley. Para la realización de este proceso se hicieron partícipes de las pesquisas a las principales entidades sociales. Con ellas se constituyó una comisión de seguimiento del proceso de regularización, que sentaría las bases de la nueva dinámica de negociación. Así, el éxito de la iniciativa se convirtió en un hecho. Las instancias públicas acometían este proyecto mientras sus interlocutores advertían de los defectos para su superación.

Esta primera fase del cambio de política se complementó con otras medidas de reforma institucional tendentes a conseguir el mejor tratamiento de los problemas de la inmigración. Entre éstas destacan: la creación, mediante el Real Decreto 1458/1991, de 11 de octubre, de la Dirección General de Migraciones; la creación, mediante el Real Decreto 152/1991, de 11 de octubre, de la Oficina Única de Extranjeros; y la creación, mediante el Real Decreto 511/92, de 4 de junio, de la Comisión Interministerial de Extranjería (Arestes, 1995). Todo esto sería el soporte para el desarrollo de las siguientes medidas que estarían más vinculadas con actuaciones de protección social e integración dentro de la sociedad de acogida.

\subsection{Institucionalización del diálogo sobre la situación de los inmigrantes}

La segunda fase de este cambio de la política del gobierno es la que se corresponde con la puesta en funcionamiento de un amplio abanico de medidas que culminaría en la elaboración del Plan General para la Integración Social de los Inmigrantes (Arestes, 1995). Ésta es una etapa de ajuste e innovación. Las medidas puestas en práctica hasta el momento registraban resultados insatisfactorios que habían de ser corregidos. A la par se propugnaban nuevas actuaciones orientadas hacia la protección social. Es una etapa marcada, también, por la organización de grandes actos a nivel internacional y por la radicalización de un fenómeno surgido con fuerza en los principios de la década: la xenofobia y el racismo organizado.

El proceso extraordinario de regularización de 1991 marcó el punto de inflexión de la política migratoria llevada a cabo por el Gobierno de la coalición socialista. Desde ese momento el panorama en esta materia varió rotundamente. Estos problemas no quedarían inscritos en la población residente previamente en España: se reconoció institucionalmente la nueva cualidad de España en cuanto al flujo migratorio internacional. Los defectos de este proceso de regularización se concretaron en la falta de medidas para garantizar la perdurabilidad de los logros obtenidos. La falta de procedimientos ágiles para prolongar la vigencia de los permisos otorgados, es decir la renovación, dio lugar a la vuelta a la situación de irregularidad de muchos extranjeros. Por otra parte, la agudización del efecto llamada supuso la llegada de nuevos aluviones de población. Todo esto trajo consigo la necesidad de tomar otras medidas destinadas a la estabilización legal de estas personas. Estas medidas se materializaron en el establecimiento de los contingentes o cupos entre los años 1993 y 1995.

No solamente fueron puestas en práctica medidas tendentes a la resolución de los problemas legales de los inmigrantes, también se promovieron iniciativas orientadas a la facilitación de la integración social. Para este fin se trataron de crear dos órganos que facilitasen el seguimiento de éstos: el Foro para la Integración Social de los Inmigrantes y el Observatorio Permanente de la inmigración. El primero era un órgano consultivo del Gobierno para la elaboración de la política en materia migratoria. El segundo era una 
herramienta que ayudase a orientar las acciones a acometer desde un punto de vista disciplinar. El Foro estaba compuesto por miembros de la administración, el sector empresarial y los interlocutores sociales representados en las organizaciones de mayor implantación en la sociedad. Al respecto de estas últimas, para garantizar la presencia de miembros de los propios colectivos afectados se hizo una división en dos categorías de grupos: por un lado, las principales organizaciones no gubernamentales que trabajasen en la materia y, por el otro, las asociaciones de los diferentes grupos de inmigrantes. Todas estas medidas se correspondían con el rumbo del debate que se estaba produciendo en la Unión Europea. Esto fue acompañado con varias iniciativas de sensibilización social que fueron coronadas con la Campaña Europea de la Juventud Contra el Racismo, la Xenofobia y el Antisemitismo. La última medida de la legislatura socialista fue la promulgación de un nuevo reglamento con el cual se pretendió solventar los defectos legales existentes.

Este fue un periodo donde el debate público, sobre los problemas de los inmigrantes, fue desarrollado como nunca antes se había hecho en la historia. La predisposición del Gobierno al diálogo fue el principal cimiento de este fenómeno. Sacar a la luz los argumentos barajados por los interlocutores supuso la mejor resolución de un conflicto que se estaba cocinando en la oscuridad. La situación provocada por los defectos del marco legal existente tendía a ser cada vez más crítica y con difícil solución.

\subsection{La regulación del fenómeno migratorio por el mercado}

La situación creada tras la institucionalización del debate público sobre la inmigración se caracterizó por el abandono de los presupuestos idealistas del entorno gubernamental. Tras la constitución del gobierno de 1996, las propuestas realizadas hasta entonces quedaron en suspenso y el fenómeno de la xenofobia y el racismo creció de forma escandalosa. A duras penas la actividad de interlocución no fue animada hasta los debates que llevaron a la firma del Tratado de Ámsterdam y el Consejo de Tampere. Fue entonces, con la aproximación al proceso electoral del año 2000, cuando se desarrolló un debate sin precedentes que acabaría en la promulgación de la Ley 4/2000, caracterizada por su grado amable y aperturista ante el fenómeno migratorio. Posteriormente, de forma inmediata, con el arrepentimiento gubernamental, la expectativa creada con esta norma fue malograda con un conjunto de medidas muy restrictivas destinadas al control de flujos. Con la justificación del necesario control del flujo migratorio, se reformó sucesivamente la Ley de Extranjería.

La filosofía de este periodo se caracterizó por el desentendimiento de los poderes del Estado sobre esta materia. Sólo trataba de entenderse esta realidad sobre presupuestos de interés económico. Claramente, se estaba confiando esta realidad a la capacidad reguladora del mercado. Aunque en la última década se crearan muchas organizaciones sobre esta temática, los órganos de interlocución y consulta del Gobierno gozaban de menos autonomía. Además, en ellos se limitaba, progresivamente, la concurrencia plural de la participación cívica. El crecimiento de entidades cívicas se debió más al crecimiento del flujo migratorio que a las expectativas proporcionadas por el marco de interlocución social sobre esta materia.

Todo esto ha tratado de ser recompuesto por el gobierno de la presente legislatura. La estrategia seguida, en un escenario de aguas tan procelosas, se ha fundamentado en el relanzamiento de la interlocución a todos los niveles, tanto de las administraciones como de éstas con la sociedad. Los resultados aún son difíciles de evaluar. 


\subsection{La consolidación del debate público institucionalizado de la inmigración}

El crecimiento del interés de la realidad migratoria en el debate público estuvo motivado por la trascendencia de este fenómeno, que en los primeros años de este siglo se caracterizó por el fuerte y acelerado incremento de la población inmigrante en España. En este país, el número de extranjeros procedentes del exterior de la Unión Europea se multiplicó por diez entre los años 2000 y 2004 . Fenómeno claramente motivado por la fuerte presión de la mecánica internacional de la población y los defectos de la política nacional de control de flujos. La situación creada con esta dinámica evidenciaba, ante la opinión pública y el discurso político, la incompetencia de las instituciones gubernamentales sobre esta materia. Las líneas de trabajo, seguidas durante las dos legislaturas precedentes, se caracterizaron por el descuido y la clara despreocupación. El Programa Global de Regularización y Coordinación de la Extranjería, de aspectos muy controvertidos en la primera redacción de su anteproyecto, sólo fue útil como declaración de principios. Este instrumento nunca fue aplicado de forma eficiente. Por otra parte, la tendencia al endurecimiento de la legislación sobre la extranjería impidió el acceso a la situación regular a la mayoría de las personas llegadas nuestro país mediante la dinámica de los flujos migratorios. Así, en la primera etapa de la globalización del mercado laboral la sociedad española homologó sus condiciones con la de los países del entorno continental.

El cambio de tendencia en esta materia se produciría con la formación del Gobierno de la Octava Legislatura. La proclama de partida de las instancias comprometidas en esta etapa contempló la ampliación y dinamización de todas las esferas del debate público y de la interlocución social y política. Frente a los retos del nuevo periodo se consideró la urgencia del compromiso de la generalidad de las instituciones públicas y de las organizaciones cívicas. Con las deficiencias del marco regulador de la extranjería y las prácticas políticas, que se fundaron en el beneficio y la benevolencia del papel regulador del mercado, se hicieron visibles los riesgos introducidos para la cohesión social, la sostenibilidad del desarrollo económico y el bienestar de la generalidad de la ciudadanía. En aquellos momentos las migraciones ya eran un factor económico de extrema importancia. Con el crecimiento negativo del movimiento natural de la población y el fuerte crecimiento de las razones de dependencia la llegada de inmigrantes era imprescindible. Aquí, lo importante fue aminorar los efectos negativos de estos procesos. Entre ellos, la exclusión social y el conflicto intercultural.

Para reducir las posibilidades de los efectos señalados fueron promovidas varias iniciativas. Todas ellas caracterizadas por los esfuerzos de interlocución. La gravedad de la situación creada y las condiciones existentes obligaban a ello. La contingencia del apoyo parlamentario no era del todo fiable y las medidas que debían ser promovidas necesitaban del mayor refuerzo social posible. En tal escenario, las primeras líneas de trabajo fueron la adaptación del marco legal con un nuevo reglamento de extranjería y su correspondiente procedimiento extraordinario de regularización. Formas de proceder que se vieron guiadas por las correspondientes dinámicas de concertación cívica. En ellas cumplieron un papel fundamental los soportes del Foro para la Integración Social de los Inmigrantes, cuya actividad y competencia fue relanzada en aquellos momentos, y las diferentes comisiones que sobre la marcha fueron surgiendo para hacer el seguimiento de estos protocolos.

La trascendencia de las prácticas destinadas a la modificación del marco legal no sólo beneficiaron a las comunidades afectadas. Con ellas el marco institucional de participación fue reforzado. Ocasión que hizo evidente la eficiencia de la concurrencia 
discursiva en la superación de los desafíos sociales. En aquellos momentos, gracias a esta forma de proceder, se consiguieron resolver muchos problemas de la práctica administrativa. Asuntos como la debida eficiencia del control de las prácticas irregulares en el marco de las relaciones laborales fueron tratados con mucha eficacia y sin perjuicio para nadie.

Junto a todo lo observado, se debe destacar como tras la consolidación de este escenario de interlocución, fueron creados nuevos instrumentos que complementaban a los existentes. Entre éstos, hay que tener en cuenta el nuevo diseño y reconfiguración de las instancias administrativas del Estado, donde se desarrollaron otros instrumentos de estudio y actuación como ha sido el Observatorio Español del Racismo y la Xenofobia, que complementa a la labor de todas las instancias mencionadas, y la Comisión Estatal contra la violencia, el racismo, la xenofobia y la intolerancia en el deporte. En esta línea de trabajo es obligada la apreciación de la promoción de las iniciativas en todos los ámbitos territoriales de la estructura orgánica del Estado. En ello, sobresalen las labores destinadas a la activación de las actuaciones de las comunidades autónomas y las corporaciones locales. Como referencias de mayor trascendencia no se puede dejar de destacar el Plan Estratégico de Ciudadanía e Integración 2007-2010, que condensa lo recogido hasta esta línea y abre expectativas muy fructíferas para nuevas intervenciones, y el Pacto de Estado sobre la Inmigración propuesto por la Fundación Empresa y Sociedad.

\section{CONCLUSIONES}

De los resultados de las aproximaciones presentadas en esta comunicación podemos apreciar, tal como lo hizo Habermas en la ética del discurso, que el proceso generador de los principios del orden existente y de la moralidad de la sociedad entraña una mecánica circular de auto-legitimación instituida por reconocimiento mutuo a través de la lógica del diálogo. Este principio de democracia es el paso útil y necesario para conseguir la base de legitimidad de las leyes, ya que son aceptadas por todos los miembros del entorno social. Por otra parte, este procedimiento entraña la base de la lógica de autodeterminación de los sujetos y de los actores sociales. Sólo a través del discurso éstos pueden reconocerse mutuamente como participantes que comparten la plenitud de sus facultades como sujetos de derecho y que las ejercen en homogeneidad de condiciones.

En el estudio de este fenómeno se debe partir de la consideración de la autorreflexión de la sociedad de acogida sobre las contradicciones de sus principios rectores. En los movimientos sociales aquí comprometidos no se estaban sentando nuevos paradigmas sobre la organización del orden social. Sólo se ha demandado la subsanación de las deficiencias que la condición del inmigrante hacía evidentes. En el desarrollo de las acciones de presión social, el extranjero no era portador de un nuevo modelo de práctica reivindicativa. El contenido de sus demandas estaba definido por la estructura conceptual del orden existente. Las pautas organizativas seguían los procedimientos utilizados por otras movilizaciones cívicas del entorno donde éstos eran acogidos. De por sí, dada la inexistencia de preceptos inmanentes de legitimidad desconocidos hasta entonces, los extranjeros carecían de toda facultad, o predisposición, para poder ejercer una presión de naturaleza innovadora sobre los poderes públicos. Ésta debía ser partícipe de lo predispuesto en los parámetros del entorno donde habrían de formularse. Nuestra sociedad, como habría de corresponder a todo sistema democrático, está dotada de los mecanismos de actuación frente a los poderes públicos y al orden social establecido. El desarrollo de este tipo de acciones se debe someter 
a la lógica y la gramática de la lógica discursiva. En definitiva, el origen de las protestas se encuentra en el interior del orden existente. Fuera de esta esfera, la fricción entre intereses colectivos queda sumida en un halo de oscuridad e incertidumbre.

En resumidas cuentas, la emergencia del fenómeno analizado en este estudio, tiene su razón de ser en la percepción de la contradicción existente entre los principios legitimadores del orden vigente y la realidad padecida por los inmigrantes. Esta circunstancia sólo capacita a mantener una actitud reactiva a los sectores sociales participantes en la constitución de esta realidad. Sólo estos pueden sentirse contravenidos por los resultados obtenidos en estos tipos de procesos. Así, podemos observar cómo esta mecánica surge más de los sectores solidarios que de la concienciación de los afectados ante su realidad. La propia condición de actor foráneo deja a los sujetos concernidos en situación de enajenación de su realidad. A pesar de las dificultades para el desarrollo de sus vidas, se da la circunstancia de que éstos, en muchos casos, no llegan a apercibirse de la injusticia de su situación. En esto influye, enormemente, el hecho de encontrarse éstos en situaciones más favorables a las mantenidas, previamente, en sus países de origen. En todo esto también influyen, poderosamente, el carácter individualista del proyecto migratorio, que acomete cada uno de los interesados, y la fuerza de las necesidades de estas personas. En verdad, parten de una férrea predisposición al trabajo donde se asienta una fuerte indisposición a cualquier otro tipo de actividad.

\section{BIBLIOGRAFÍA}

ABERCROMBIE, N.; HILL, S. y TURNER, B. S. (1987): La tesis de la ideología dominante, Madrid, Siglo XXI.

ALBERONI, F. (1985): Movimientos e instituciones: teoría general, Madrid, Nacional.

ÁlVAREZ JUNCO, J. (1995): Movimientos sociales en España. Del modelo tradicional a la modernidad post-franquista, Madrid, Instituto Universitario Ortega y Gasset.

ARANGUREN, J. L., et al. (1983): Comunidades sociales adultas (grupos sociales intermedios), Madrid, Mezquita.

ARENDT, A. (1997): ¿Qué es la política?, Barcelona, Paidós.

- (1987): De la historia a la acción, Barcelona, Paidós.

BAKER, D.G. (1983): Race Ethnicity and Power, London, E. Routledge and Kegal Paul.

BARNES, S.; KAASE, M., et al. (1979): Political Action: Mass Participation in Five Western Democracies, Beverly Hills, C.A., Sage Publications.

BASTERNIER, A. y DASSETO, F. (1991): Immigrations et Nouveaux Pluralismes, Bruselas, Editions Universitaires de Boeck.

BAUMAN, Z. (2005): Modernidad y ambivalencia, Barcelona, Anthropos.

BERGALLI, R. (2006): Flujos migratorios y su descontrol, Barcelona, Anthropos.

BOBBIO, N. (1992): Estado, gobierno y sociedad: por una teoría general de la política, México, F.C.E.

BOUZA, F. (1994): "Debatiendo con Norbert Elias: entre el yo y el nosotros", Revista Española de Investigaciones Sociológicas, $\mathrm{n}^{\mathrm{0}} 65$.

CACHÓN, L. (2008): "La integración de y con los inmigrantes en España: debates teóricos, políticas y diversidad territorial", Política y Sociedad, vol. 45, no. 1, pp. 205-234.

CAMPS, V. (1996): El malestar de la vida pública, Barcelona, Grijalbo.

COHEN, J. L. y ARATO, A. (2001): Sociedad Civil y Teoría Política, México, F.C.E.

DALTON, R. J. y KUECHLER, M. (1992): Los nuevos movimientos sociales. Un reto al orden político, Valencia, Edicions Alfons el Magnànim, Institutió Valenciana D’Estudis i Investigatió. 
ELIAS, N. (1987): El proceso de la civilización. Investigaciones sociogenéticas y psicogenéticas, México, F.C.E.

- (2000): La sociedad de los individuos, Barcelona, Península.

ETZIONI, A. (2001): La tercera vía hacia una buena sociedad: Propuestas desde el comunitarismo, Madrid, Trotta.

FOUCAULT, M. (1996): Genealogía del racismo, La Plata, Altamira.

- (1984): La arqueología del saber, México, Siglo XXI.

GELLNER, E. (1987): Condiciones de la libertad. La sociedad civil y sus rivales, Barcelona, Paidós.

GIDDENS, A. (1993): Consecuencias de la modernidad, Madrid, Alianza.

- (1983): La estructura de clases en las sociedades avanzadas, Madrid, Alianza.

GINER, S. (1983): "Crisis y renovación de la comunidad", en: GINER, S. (coord.) Comunidades sociales adultas, Madrid, Mezquita, pp. 21-30.

GINER, S. y PÉREZ IRUELA, M. (1988): El corporatismo en España, Barcelona, Ariel.

GONZÁLEZ ENRÍQUEZ, C. (2008): Los inmigrantes ante la inmigración, Madrid, OPI, Ministerio de Trabajo e Inmigración.

GUSFIELD, J.R. (1981): The culture of public problems: drinking-driving and the symbolic order, Chicago, University of Chicago Press.

HABERMAS, J. (2004): Historia y crítica de la opinión pública, Barcelona, Gustavo Gili.

- (2004): La inclusión del otro. Estudios de teoría política, Barcelona, Paidós.

- (1998): Teoría de la acción comunicativa, Vol. I, Madrid, Taurus.

HEIDEGGER, M. (1988): Identidad y diferencia, Barcelona, Anthropos.

HUNTINGTON, S. P. (1997): ¿Choque de civilizaciones?, Buenos Aires, Paidós.

HUNTINGTON, S. P. y BERGER, P. L. (2002): Globalizaciones múltiples. La diversidad cultural en el mundo contemporáneo, Barcelona, Paidós.

INGLEHART, R. (2006): Modernización, cambio cultural y democracia: La secuencia del desarrollo, Madrid, Siglo XXI.

JAMESON, F. (1998): Estudios culturales. Reflexiones sobre el multiculturalismo, Buenos Aires, Paidós.

JOHNSTON, H., et al. (1995): "Identidades, ideologías y vida cotidiana en los nuevos movimientos sociales", en Laraña, E. (comp.) Los nuevos movimientos sociales, Madrid, CIS.

KAESE, M. (1992): "Movimientos sociales e innovación política", en Dalton, R. J., y Kuechler, M. Los nuevos movimientos sociales. Un reto al orden político, Valencia, Edicions Alfons el Magnànim, Institutió Valenciana D'Estudis i Investigatió, pp. 125-126.

KERBO, R. H. (2003): Estratificación social y desigualdad, Madrid, McGraw-Hill.

KINLICKA, W. (2004): Estados, naciones y culturas, Córdoba, Almuzara.

LEVINAS, E. (2002): Totalidad e infinito. Ensayo sobre la exterioridad, Salamanca, Sígueme.

LEWIS, O. (1972): La cultura de la pobreza, Pobreza, burguesía y revolución, Barcelona, Anagrama.

LUHMANN, N. (2000): La realidad de los medios de masas, Barcelona, Anthropos.

McADAM, D. (1982): Political Process and the Development of Black Insurgency, Chicago, IL., University of Chicago Press.

MELUCCI, A. (1989): Nomads of the present. Social movements and individual needs in contemporary society, London, Hutchinson Radius.

NOELLE-NEUMANN, E. (2003): La espiral del silencio, Barcelona, Paidós.

OFFE, C. (1988a): "La atribución de un estatus público a los grupos de interés: observaciones sobre el caso de Alemania Occidental", en BERGER, S. (comp.) La organización de los grupos de interés en la Europa Occidental. El pluralismo, el corporativismo y la transformación de la política, Madrid, Ministerio de Trabajo y Seguridad Social.

- (1988b): Partidos políticos y nuevos movimientos sociales, Madrid, Sistema.

- (1990): Contradicciones en el Estado de Bienestar, Madrid, Alianza.

- (1992): La gestión política, Madrid, Ministerio de Trabajo y Seguridad Social.

PAJARES, M. (2009): Inmigración y mercado de trabajo. Informe 2009, Madrid, OPI, Ministerio de

Trabajo e Inmigración. 
PARK, R. E. (1999): La ciudad y otros ensayos de ecología urbana, Barcelona, Serbal.

PAUGAN, S. (2007): Las formas elementales de la pobreza, Madrid, Alianza.

SIMMEL, G. (2001): El individuo y la libertad. Ensayos de crítica de la cultura, Barcelona, Península.

- (1998): Les pauvres, Paris, Presses Universitaires de France (PUF).

- (2003): La filosofía del dinero, Granada, Albolote.

- (2006): Problemas fundamentales de la filosofía, Sevilla, Espuela de Plata.

SOLÉ, C.; PARELLA, S. y CALVANTI, L. (2008): Nuevos retos del transnacionalismo en el estudio de las migraciones, Madrid, OPI, Ministerio de Trabajo e Inmigración.

TARROW, S. (1991): "Struggle, Politics, and Reform: Collective Action, Social Movements, and Cycles of protest", Western Societies Program, Occasional Paper No. 21 (2nd edition), New York, Center for International Studies, Cornell University.

TAYLOR, CH. (2003): El multiculturalismo y la política del reconocimiento, México, F.C.E.

- (2006): Imaginarios sociales modernos, Barcelona, Paidós.

TILLY, CH. (1996): Citizenship, identity and social history, Cambridge, Cambridge University Press.

TOCQUEVILLE, A. (2003): Memoria sobre el pauperismo, Madrid, Tecnos.

TOURAINE, A. (1993): Crítica de la modernidad, Madrid, Temas de hoy.

- (1996): Los mass media: ¿nuevo foro político o destrucción de la opinión pública?, Barcelona, Generalitat de Catalunya, Centre d'Investigació de la Comunicació.

- (1990): Movimientos sociales hoy, Barcelona, Ed. Hacer.

- (1994): ¿Que es la democracia?, Madrid, Temas de hoy.

TOYNBEE, A. (1984): Guerra y civilización, Madrid, Alianza.

WIEVIORKA, M. (2007): La primavera de la política. Ideas para acabar con el declive de la democracia tradicional, Barcelona, La Vanguardia.

WIEVIORKA, M. (1997): Une société fragmentée? Le multiculturalisme en débat, Paris, La Découverte.

\section{Breve currículo:}

\section{Tomás Pedro Gomariz Acuña}

Licenciado y doctor en Sociología por la Universidad Complutense. Profesor e investigador en la Universidad Rey Juan Carlos, Miembro del Grupo de Investigaciones y Estudios Sociales Avanzados (GIESA) de la Universidad Rey Juan Carlos. Investigador del Instituto Ciencia y Sociedad. Especialista en el estudio del fenómeno migratorio, la exclusión social, el conflicto interétnico e intercultural, las instituciones políticas y los movimientos sociales, las técnicas y los métodos de investigación y la teoría sociológica. 